\title{
One-stop PCI+TAVR intraoperative circulatory collapse and successful rescue of 1 case report
}

\author{
Hang Zhang ${ }^{1}$, Jinghui $\mathrm{An}^{1}$, SU Liu ${ }^{1}$, Qianli Ma ${ }^{1}$, and Feng-wu Shi ${ }^{1}$ \\ ${ }^{1}$ Affiliation not available
}

August 9, 2021

\begin{abstract}
Background and Aim: We report a case of severe aortic stenosis accompanied by severe aortic insufficiency complicated with coronary heart disease who underwent one-stop PCI+TAVR intraoperative circulation collapse and was successfully rescued. Case Summary:A 73-year-old male patient with severe aortic stenosis with severe aortic insufficiency and coronary heart disease underwent one-stop TAVR+PCI with the aid of Cardiopulmonary bypass(CPB). PCI was successfully performed in the patient, and a $2.5^{*} 33 \mathrm{~cm}$ Nano coronary stent was implanted. No residual stenosis was observed in angiography. During TAVR, A VenusA L26mm interventional valve was inserted, and the valve slid slightly downward with poor position. Aortic root angiography showed A large amount of regurgitation and A progressive decrease in blood pressure, which could not be maintained even after the application of vasoactive drugs. Chest compressions were performed, and the extracorporeal circulation machine was opened to assist circulation. In the same way, A Venus-A L26mm interventional valve was placed in the previous valve. Aortic root angiography was performed without regurgitation. TEE examination showed that the valve opened and closed well and the orifice velocity was normal without regurgitation. After surgery, the patient returned to ICU smoothly. Conclusion: One-stop PCI+TAVR is a reasonable method for the treatment of aortic valve disease complicated with coronary heart disease. Cardiopulmonary bypass (CPB) is an effective method to deal with circulatory collapse in time.
\end{abstract}

the title of the paper: One-stop PCI+TAVR intraoperative circulatory collapse and successful rescue of 1 case report

author/co-authors contact details: Hang Zhang, Department of Cardiac Surgery, No.215, Heping West Road, Xinhua District,050000 Shijiazhuang, China,Email: 190361059@qq.com

author/co-authors affiliations: The Second Hospital of Hebei Medical University

corresponding author email and affiliation: Feng-wu Shi,Department of Cardiac Surgery, No.215, Heping West Road, Xinhua District,050000 Shijiazhuang, China,Email:shifengwu65@163.com

\section{CONFLICT OF INTERESTS}

The authors declare that there are no conflict of interests.

\section{Ethical review}

This study was approved by the Medical Ethics Committee of the Second Hospital of Hebei Medical University (approval number: 2021-P030).

One-stop PCI+TAVR intraoperative circulatory collapse and successful rescue of 1 case report Hang Zhang ${ }^{1}$, Jing-hui $\mathrm{An}^{1}$, Su Liu ${ }^{1}$, Qian-li Ma ${ }^{1}$, Feng-wu Shi ${ }^{1}$

Department of Cardiac Surgery, the Second Hospital of Hebei Medical University, Shijiazhuang, China 


\begin{abstract}
Background and Aim: We report a case of severe aortic stenosis accompanied by severe aortic insufficiency complicated with coronary heart disease who underwent one-stop PCI+TAVR intraoperative circulation collapse and was successfully rescued.
\end{abstract}

Case Summary: A 73-year-old male patient with severe aortic stenosis with severe aortic insufficiency and coronary heart disease underwent one-stop TAVR + PCI with the aid of Cardiopulmonary bypass(CPB). PCI was successfully performed in the patient, and a $2.5^{*} 33 \mathrm{~cm}$ Nano coronary stent was implanted. No residual stenosis was observed in angiography. During TAVR, A Venus-A L26mm interventional valve was inserted, and the valve slid slightly downward with poor position. Aortic root angiography showed A large amount of regurgitation and A progressive decrease in blood pressure, which could not be maintained even after the application of vasoactive drugs. Chest compressions were performed, and the extracorporeal circulation machine was opened to assist circulation. In the same way, A Venus-A L26mm interventional valve was placed in the previous valve. Aortic root angiography was performed without regurgitation. TEE examination showed that the valve opened and closed well and the orifice velocity was normal without regurgitation. After surgery, the patient returned to ICU smoothly.

Conclusion: One-stop PCI+TAVR is a reasonable method for the treatment of aortic valve disease complicated with coronary heart disease. Cardiopulmonary bypass $(\mathrm{CPB})$ is an effective method to deal with circulatory collapse in time.

\title{
KEY WORD
}

TAVR, PCI, circulatory collapse, CPB

\section{Correspondence}

Feng-wu Shi,Department of Cardiac Surgery, No.215, Heping West Road, Xinhua District,050000 Shijiazhuang, China

Email: shifengwu65@163.com

\section{Conflict of interests}

The authors declare that there are no conflict of interests.

\section{Ethical review}

This study was approved by the Medical Ethics Committee of the Second Hospital of Hebei Medical University (approval number: 2021-P030).

\section{1 | INTRODUCTION}

As we all know, TAVR surgery has become the first-line treatment for aortic valve disease, and the therapeutic effect of one-stop PCI+TAVR surgery is also not negligible. However, TAVR or one-stop PCI+TAVR for elderly, high-risk patients with aortic valve disease complicated with multiple diseases still face great risks, and circulatory collapse is one of the common intraoperative adverse events. In the face of circulatory collapse, timely solution and reasonable response are the key to bring patients to safety, and cardiopulmonary bypass is an effective measure to escort TAVR/ one-stop PCI+TAVR surgery and deal with circulatory collapse events. Now, we report a case of successful rescue after circulation collapse during the one-stop PCI+TAVR operation in our center as follows.

\section{| Case presentation}

The 73-year-old male patient was admitted to hospital due to intermittent chest tightness and shortness of breath for 8 months, which aggravated for half a month. Physical examination: thick breathing sound in both lungs, wet rales in both lungs. Heart rate is 82 beats per minute, rhythmic, systolic murmurs can be heard in the first auscultation area of the aortic valve, and diastolic murmurs can be heard in the second 
auscultation area of the aortic valve. Abdominal distention, tenderness in the liver area, no rebound pain, not touched under the liver, spleen and rib. Slight pitting edema in both lower extremities. On admission, echocardiography confirmed severe stenosis of the main artery valve with severe insufficiency. The mean transvalvular pressure difference was $45 \mathrm{mmHg}$, the flow velocity on the aortic valve was $425 \mathrm{~cm} / \mathrm{s}$, and EF value was $35 \%$. Computed tomography angiography revealed a TYPE1 bilobular valve with a fusion ridge in the right and no coronary sinus, small French sinus structure, low height of the left and right coronary openings from the French sinus, small heart Angle, large left ventricle, and weak local myocardium at the apex (Figure 1-2). Coronary angiography showed that the longest stenosis of the proximal LAD was about 95\%. No obvious abnormalities were observed in LCX and RCA.

\section{| Surgical technique}

PCI was successfully performed in the patient, and a $2.5^{*} 33 \mathrm{~cm}$ Nano coronary stent was implanted. No residual stenosis was observed in angiography(Figure 3). During TAVR, A Venus-A L26mm interventional valve was inserted, and the valve slid slightly downward with poor position. Aortic root angiography showed A large amount of regurgitation (Figure 4)and A progressive decrease in blood pressure, which could not be maintained even after the application of vasoactive drugs. Chest compressions were performed, and the extracorporeal circulation machine was opened to assist circulation. In the same way, A Venus-A L26mm interventional valve was placed in the previous valve. Aortic root angiography was performed without regurgitation(Figure 5). TEE examination showed that the valve opened and closed well and the orifice velocity was normal without regurgitation. After surgery, the patient returned to ICU smoothly.

\section{| DISCUSSION}

With the acceleration of population aging process and the change of people's living structure, the incidence of aortic valve disease complicated with coronary heart disease is gradually increasing. According to statistics, the incidence of aortic stenosis combined with coronary heart disease can reach $50 \%{ }^{[1-3]}$. Aortic stenosis and coronary heart disease are complementary to each other in the course of disease. On the one hand, aortic stenosis can cause left ventricular ejection obstruction, blood flow obstruction, left ventricular hypertrophy, myocardial oxygen consumption increases, aggravate the symptoms of coronary heart disease in patients. On the other hand, severe coronary stenosis aggravates the degree of heart failure and further reduces left ventricular ejection, which further aggravates the symptoms of aortic stenosis. The two diseases interact with each other, ultimately exacerbating the progression of the patient's overall disease and accelerating the development of irreversible events at the end of the clinical stage.

One-stop PCI+TAVR surgery is an effective means to solve the problems of aortic valve disease and coronary artery stenosis. One-stop PCI+TAVR can solve two lesions in one operation at the same time, avoiding the difficulties and risks caused by the second operation ${ }^{[4-5]}$. At the same time, one-stop PCI+TAVR surgery can shorten the waiting time for surgery and hospital stay of patients, which greatly realizes the effective saving of medical resources.

The present case is a 73-year-old male patient with severe aortic stenosis with severe aortic insufficiency and coronary heart disease.After comprehensive evaluation and analysis by the TAVR team of our center, it was unanimously agreed that the patient should not be treated with traditional thoracotomy. Finally, a one-stop PCI+TAVR surgery program was formulated in the hybrid operating room of cardiac surgery under general anesthesia and cardiopulmonary bypass. This cases PCI procedure smoothly, but TAVR intraoperative circulation collapse event happened, the main consideration in patients with preoperative heart is larger, difference of cardiac function, cardiac reserve capacity is low, coupled with the first step in valve position after release, and diastolic appear a large number of reflux time heart can't bear so big blow, circulating to collapse. But as a result of preoperative patients with extracorporeal circulation pathway is established, when the circulatory collapse coming, in the emergency rescue of chest compressions immediately and opening the extracorporeal circulation at the same time, for their own blood circulation of auxiliary, guarantee the stability of the patients with hemodynamic, reasonable decisions for the next performer to win the precious time, realized in the true sense of the overall operation of the escort, Bring the patient to safety. Therefore, 
cardiopulmonary bypass is an important measure to save the catastrophic complications of TAVR.

\section{| CONCLUSION}

At present, although it is difficult and challenging to perform one-stop PCI+TAVR surgery for patients with poor general conditions, one-stop PCI+TAVR can still achieve good efficacy with the auxiliary support of cardiopulmonary bypass technology. In conclusion, one-stop PCI+TAVR is a reasonable method for the treatment of aortic valve disease complicated with coronary heart disease, and cardiopulmonary bypass is an effective means to timely deal with circulatory collapse events during the operation.

\section{REFERENCES}

1. Goel SS, Ige M, Tuzcu EM, et al. Severe aortic stenosis and coronary artery disease-implications for management in the transcatheter aortic valve replacement era: a comprehensive review $[\mathrm{J}]$. J Am Coll Cardiol,2013,62(1):1-10.

2. Cao D, Chiarito M, Pagnotta P, Reimers B, Stefanini GG. Coronary revascularisation in transcatheter aortic valve implantation candidates: why, who, when? [J] Interv Cardiol, 2018,13(2):69-76.

3. Chodór P, Wilczek K, Włoch $\mathrm{E}$, et al. Impact of coronary artery disease on outcomes of severe aortic stenosis treatment with transcatheter aortic valve implantation[J]. Postępy w Kardiologii Interwencyjnej,2019,15(2):167-175.

4. Griese DP, Reents W, Tóth A, et al. Concomitant coronary intervention is associated with poorer early and late clinical outcomes in selected elderly patients receiving transcatheter aortic valve implantation[J]. Eur J Cardiothorac Surg,2014,46(1):e1-7.

5. Penkalla A, Pasic M, Drews T, et al. Transcatheter aortic valve implantation combined with elective coronary artery stenting: a simultaneous approach[J]. Eur J Cardiothorac Surg,2015,47(6):1083-1089.

Figure:

Figure 1 Computed tomography angiogram shows the TYPE1 bilobular valve.

Figure 2 Computed tomography angiogram shows the TYPE1 bilobular valve.

Figure 3 No residual stenosis was observed in angiography.

Figure 4 Aortic root angiography shows A large amount of regurgitation after the first valve inserted. Figure 5 Aortic root angiography shows no regurgitation after the second valve inserted.

\section{Hosted file}

FIGURE 1.docx available at https://authorea.com/users/429871/articles/533473-one-stop-pcitavr-intraoperative-circulatory-collapse-and-successful-rescue-of-1-case-report

\section{Hosted file}

FIGURE 2.docx available at https://authorea.com/users/429871/articles/533473-one-stop-pcitavr-intraoperative-circulatory-collapse-and-successful-rescue-of-1-case-report

\section{Hosted file}

FIGURE 3.docx available at https://authorea.com/users/429871/articles/533473-one-stop-pcitavr-intraoperative-circulatory-collapse-and-successful-rescue-of-1-case-report

\section{Hosted file}

FIGURE 4.docx available at https://authorea.com/users/429871/articles/533473-one-stop-pcitavr-intraoperative-circulatory-collapse-and-successful-rescue-of-1-case-report

\section{Hosted file}


FIGURE 5.docx available at https://authorea.com/users/429871/articles/533473-one-stop-pcitavr-intraoperative-circulatory-collapse-and-successful-rescue-of-1-case-report 